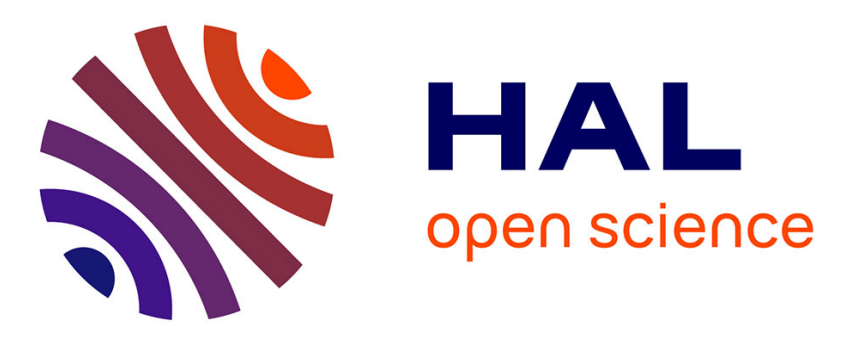

\title{
Wall shear stress and pressure sensors development for active flow control
}

\author{
Dimitrios Tsamados, David Meunier, Mourad Laghrouche, Jumana
}

Boussey-Said, Sedat F. Tardu

\section{To cite this version:}

Dimitrios Tsamados, David Meunier, Mourad Laghrouche, Jumana Boussey-Said, Sedat F. Tardu. Wall shear stress and pressure sensors development for active flow control. SPIE International Symposium Micromachining and Microfabrication, Jan 2004, San Jose, CA, United States. pp.524533, 10.1117/12.524533 . hal-00262240

\section{HAL Id: hal-00262240 \\ https://hal.science/hal-00262240}

Submitted on 7 Feb 2020

HAL is a multi-disciplinary open access archive for the deposit and dissemination of scientific research documents, whether they are published or not. The documents may come from teaching and research institutions in France or abroad, or from public or private research centers.
L'archive ouverte pluridisciplinaire HAL, est destinée au dépôt et à la diffusion de documents scientifiques de niveau recherche, publiés ou non, émanant des établissements d'enseignement et de recherche français ou étrangers, des laboratoires publics ou privés. 


\title{
Wall Shear Stress and Pressure Sensors Development for Active Control of Flow
}

\author{
Dimitrios M. Tsamados**†, Delphine Meunier ${ }^{\dagger}$, Mourad Laghrouche ${ }^{\dagger}$, Jumana Boussey ${ }^{\dagger}$ and Sedat Tardu ${ }^{\ddagger}$ \\ ${ }^{\dagger}$ Institut de Microélectronique, d’Electromagnétisme et de Photonique, 23 rue des Martyrs, B.P. 257,38 016 Grenoble \\ Cedex 1, France \\ ${ }^{\ddagger}$ Laboratoire des Ecoulements Géophysiques et Industriels, B.P. 53, 38402 Grenoble Cédex, France
}

\begin{abstract}
In this paper we present a technology for wall shear stress and pressure integrated sensor fabrication. Thanks to the use of SOI wafers and wafer bonding technique, we came up with an innovative technology that provides high on-chip density of sensors required for arrays utilized in numerous microfluidic applications like active control of flow. At the end some wall shear stress results are presented.
\end{abstract}

Keywords: MEMS, SOI, pressure sensors, wall shear stress sensors

\section{INTRODUCTION}

Active control of flow is a difficult task to achieve because it necessitates sensors of high sensitivity, quick response and high density of integration. For instance, the dynamic response of a pressure sensor should be fast enough to immediately detect the formation of local turbulence mechanisms of which the lifetime is of the order of the millisecond. Moreover, the use of these sensors is only interesting if they can be disposed in an array configuration with a small enough mesh to allow spatial resolution compatible with the length of the smallest boundary layer eddies, i.e. $<200 \mu \mathrm{m}$.

In addition, three parameters are fundamental for accurate understanding of complex phenomena such as turbulence or separation occurring within the boundary layer of a fluid flowing through a microchannel or tangentially to a wing surface. These parameters are wall shear stress, pressure fluctuations and temperature. Therefore, we should add to the sensors' properties mentioned above the coexistence of three different types of sensors on the same chip in order to reach our goal. For avionics and automotive applications, a big challenge is to simultaneously monitor these three parameters in order to monitor their evolution in time and space.

Since the early nineties, some teams have been working on MEMS-based silicon technology providing highly sensitive sensor arrays. Their published reports either mention high integration density of wall shear sensors [1,2], or good dynamic performance for pressure fluctuation sensing [3], but, to our knowledge, no team realized sensors complying with the necessity to co-integrate the three types of sensor arrays with good performance on the same chip.

With the help of Finite Element Analysis (FEA) tools (microfluidic, thermal and mechanical), we have determined the optimal dimensions of our sensors. This FEA approach has been developed elsewhere [4] and proved that the technology that best fits the desired specifications is the SOI one, which allows the realization of these prototypes briefly described in the following section.

\subsection{Sensors properties}

Pressure sensing is based on the use of piezoresistive gauges placed on very small diaphragms $\left(<100 \times 100 \mu \mathrm{m}^{2}\right)$. The design proposed in this paper permits the pressure sensors to operate in a differential or absolute pressure configuration. This last option necessitates the design of a specific ventilation channel, eventually pressure control

\footnotetext{
*tsamados@enserg.fr
} 
during bonding (if absolute pressure sensor is used) as well as a high degree of thin layer thickness uniformity and reproducibility when elaborating such sensors. The wall shear stress sensor's operation is based upon the principle of hot wire anemometry. The sensing element is made of polysilicon or eventually platinum resistors. The latter has to be thermally isolated from the substrate by a sealed or open cavity to minimize the heat exchange with the substrate $[4,5]$. Finally, simple miniaturized $\mathrm{p}-\mathrm{n}$ diodes have been adopted for local temperature sensing. The principle of measurement is based on the temperature dependence of the forward voltage drop in a $p-n$ junction biased at a constant current. In the following paragraphs, we present the flowchart of the adopted technology solution for the co-fabrication of the above-described sensors highlighting the specific contribution of selected technological parameters.

\section{TECHNOLOGY}

\subsection{Fabrication}

Two SOI wafers are the starting materials for the fabrication of the sensors. The first one, called "base" wafer, is a BESOI with a device layer thickness chosen equal to the pressure sensor's air-cavity depth. In case of KOH or TMAH bulk micromachining the "base, wafer should be $<100>$-oriented and p-type doped (typical resistivity range: 14$20 \Omega \mathrm{cm}$ ). In the following paragraphs we will see that the base wafer can be a regular double-sides-polished wafer.

The second or "top, wafer should be Unibond or SIMOX finished with epitaxial growth. The preferred SOI device layer thickness ranges from 0.5 to $2 \mu \mathrm{m}$, a $0.5 \mu \mathrm{m}$-thick buried oxide layer (BOX) and can be $\mathrm{n}$ or p-type doped, allowing consequently boron or phosphor ion implantation to maximize the piezoresistance coefficients of the piezoresistive gauges which are orientation dependent (in each case the "top,, wafer has to be correctly oriented prior to implantation). The first step (Fig.1\&2) consists in etching the pressure sensor cavities in the "base,, wafer using a deep reactive ion silicon etching (DRIE) or $\mathrm{KOH}$ or TMAH etching. The buried oxide of the "base,, wafer constitutes an excellent etch stop layer with respect to the $\mathrm{KOH}-\mathrm{TMAH}$ selectivity between $\mathrm{SiO}_{2}$ and $\mathrm{Si}$. This provides a nearly perfect reproducibility of the cavity depth over the whole wafer surface. The substrate's BOX can also be used as an etch barrier for DRIE process although recent etching tests carried out in our clean room show that DRIE process can give very good homogeneity of cavity depths over the whole wafer surface without the use of a SOI wafer. This is very important for the final production because it drastically reduces the cost of the sensors. During this step we also patterned the vent channels for the pressure sensor.

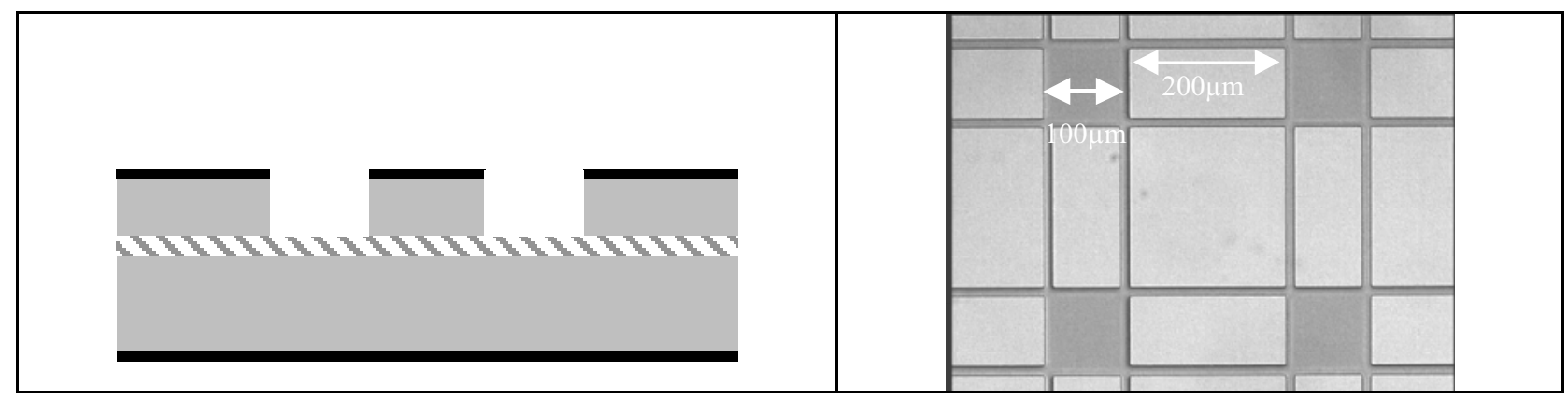

Fig.1. Pressure sensor cavity elaboration in the "base" BESOI wafer Fig.2. Top view of the base wafer after deep reactive ion by deep RIE etching of $<100>$ silicon. etching of pressure sensors' cavities and vent channels.

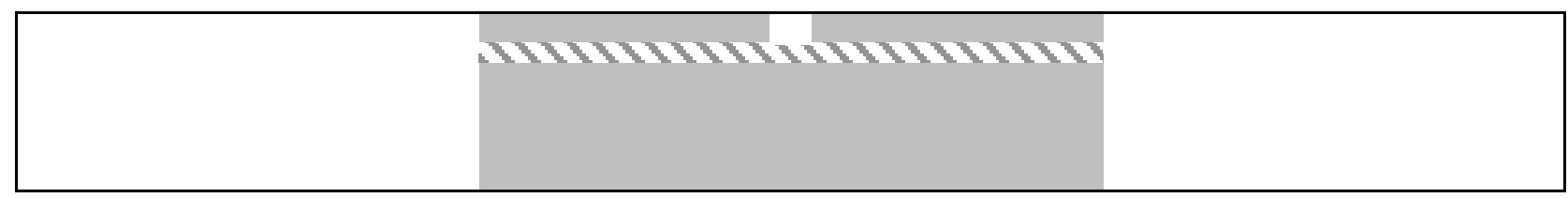

Fig.3. Patterning within the "active" SOI wafer of the cavity underneath the hot wire anemometer.

Subsequent alignment and lithography steps (No.3 step) require double-side lithography to pattern appropriate alignment features on the backside of this "base,, wafer. During the second step (Fig.3) the thermal isolation cavities on the "top,, wafer necessary for the hot wire anemometer operation are patterned. This step is conducted under the same 
technological conditions than the first step and leads to an almost perfect reproducibility of the cavity depth. In this case DRIE is preferred because it does not require a protective oxide layer for the patterning (the photo-resist suffices), contrarily to $\mathrm{KOH}-\mathrm{TMAH}$ etching. Indeed, this cavity depth becomes equal to the SOI thickness of the initial "active,, wafer.

Thorough cleaning of the wafers' surface takes place before being assembled in a substrate bonder tool. The surface preparation prior to bonding is of great importance as it is already proven by many studies [6] and great care has been taken regarding this issue. Thermal oxidation followed by special chemical treatment has been performed before bonding (Fig. 5) for rendering the wafers' surfaces hydrophilic. Thermal anneal was the next step in order to increase the bonded surface energy. Subsequently, removal of all of the "active,, wafer's silicon substrate reduces the whole pair thickness and creates the pressure sensors' membranes (Fig.4). Relatively low residual stresses are observed in the membranes after the thinning-down of the "top, wafer (Fig.7) by wet selective etching (TMAH solution). Another technique has recently being tested by utilizing chemical-mechanical polishing (CMP), a technique which is not used as stand-alone method of thinning-down but its role is complementary to TMAH etching. The first 300-400 microns of the "top, wafer's substrate are removed by CMP and the finishing is made by the TMAH solution. The reason for selecting this approach is that for removing around 400 microns of silicon several hours of etching in TMAH are necessary, risking the infiltration of TMAH into the bonding interface and the destruction of the pressure sensors' membranes by TMAH penetration through the sensors' vent channels.

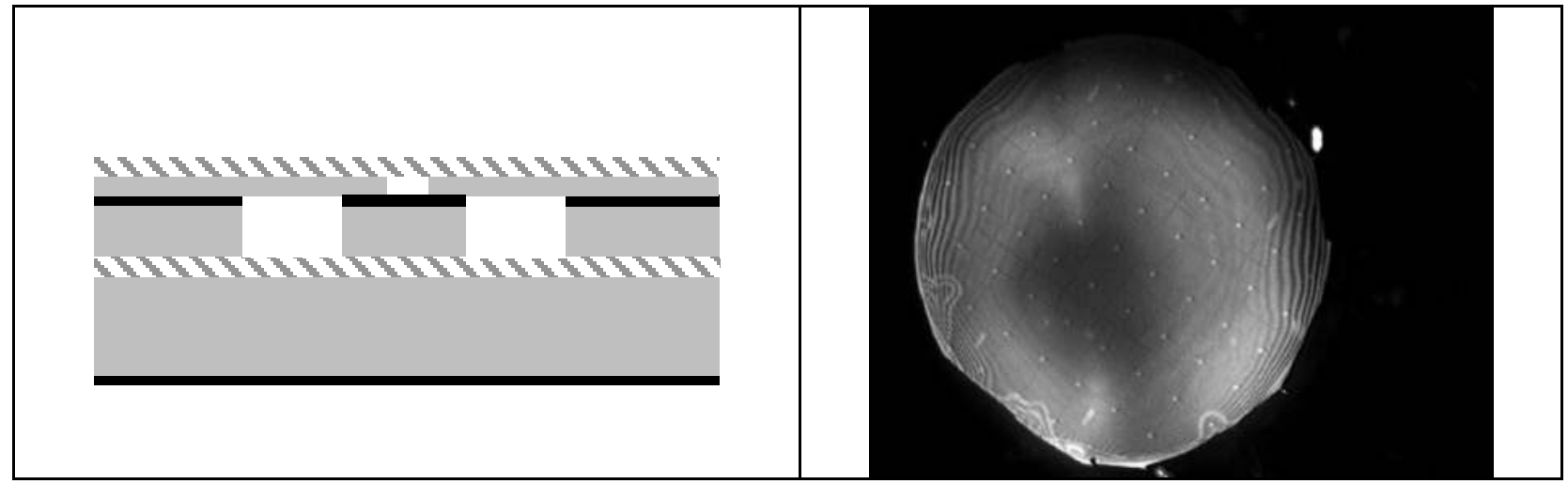

Fig.4. A new substrate is obtained by bonding together the Fig.5. Infra-red photograph of the two bonded wafers prior to above-processed followed by thinning down the upper "active" thinning-down. layer.

The next lithography step is dedicated to the patterning of the $\mathrm{p}-\mathrm{n}$ junction and the piezoresistive gauge surfaces to be implanted. A boron or phosphorus ion-implantation (dose and energy are estimated by numerical simulation using Silvaco $^{\circledR}$ ) is then conducted and followed by an activation annealing. It is important to underline that one of the advantages of this technology is that it allows piezoresistive gauges to be monocrystaline. The piezoresistance coefficient of mono-Si is higher than the corresponding one of poly-Si, a fact that confers higher sensitivity for monoSi gauges. After the ion implantation follows a deposition of a polysilicon film, p-type doped. A fifth lithography allows the hot wire resistor patterning and that of some of poly-Si gauges in order to compare their response and sensitivity to that of mono-Si ones. 


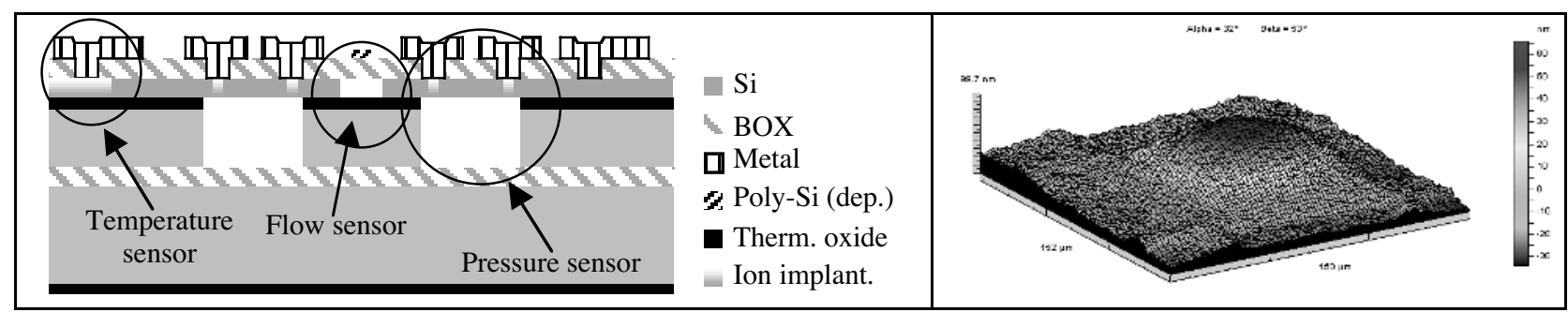

Fig.6. Schematic section view of the final structure with the 3 types of Fig. 7. Deformation of a100x100 $\mu \mathrm{m} 2$ membrane sensors co-existing on the same die. due to residual stresses (image taken with Fogale ${ }^{\circledR}$ Nanotech's ZoomSurf3D ${ }^{\mathrm{TM}}$ optical profilometer).

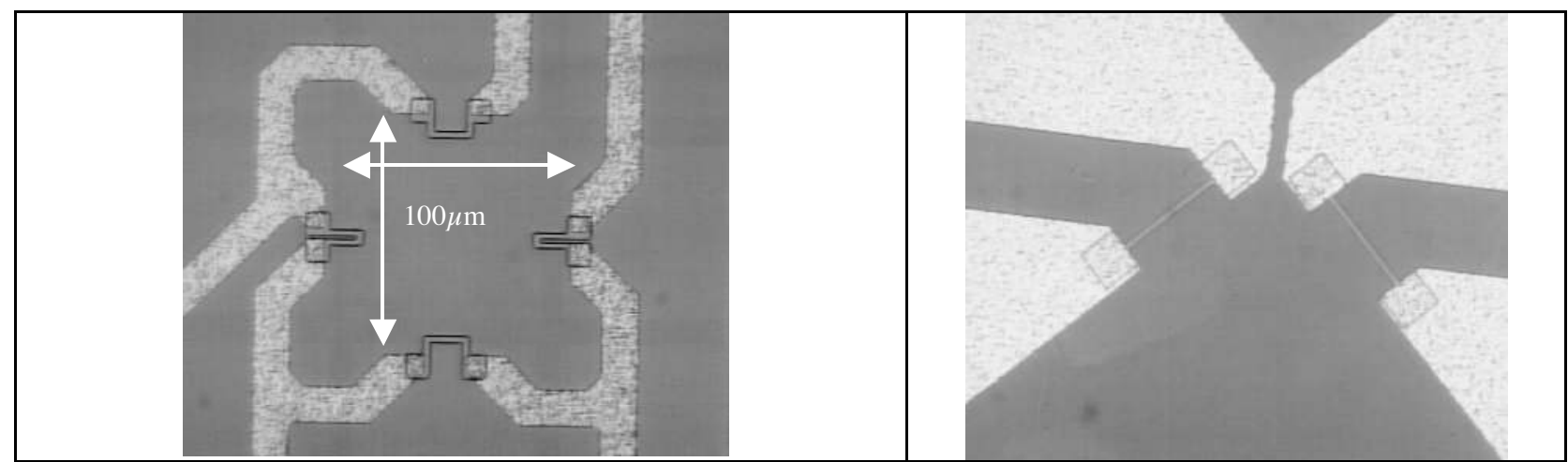

Fig. 8. Finalized pressure sensor with metallization. The cavity and the Fig. 9. Hot-wire anemometers in a 90 deg. setup. vent channels are visible underneath the thin layers of $\mathrm{SiO}_{2}$ and $\mathrm{Si}(0.6 \mu \mathrm{m}$ and $1 \mu \mathrm{m})$.

Finally, a seventh lithography is used to open the vias for the subsequent metallic contacts on the various sensors. A chrome layer is then deposited by sputtering and patterned to form the lead wires (Fig.6, 8, 9). The eighth and final lithography permits the release of the poly-Si resistors by sacrificial attack of the underlying silicon dioxide layer in order to achieve the thermal isolation needed by architectures requiring open cavities.

\section{DESIGN AND TEST}

\subsection{Design of the pressure sensor}

As it is mentioned earlier in the introduction, the pressure sensor has to comply with quite strict technical specifications in order to be suitable for use in active control of flow. First of all, the detection of small-scale air eddies necessitates a high sensitivity pressure sensor of a relatively small size. Typically the size of these eddies is of the order of 100 microns or smaller and the pressure fluctuations as low as $10^{3} \mathrm{~Pa}$ and some $10 \mathrm{KHz}$ of frequency. As a result the design of the pressure sensor had to be carried out carefully by adapting one of the already existing solutions for pressure sensing (piezoresistive gauge sensor) to the sensitivity, size and response time imposed by the application.

Finite element analysis (FEA) is the first candidate when it comes to the sensor's initial design and later to its optimization. A parametric 3D model of the pressure sensor has been created using ANSYS ${ }^{\circledR}$ Multiphysics FEA (Fig. $10,11,12$ ) tool in order to numerically simulate the sensor's behaviour for different designs and different conditions of operation (e.g. pressure change). At the same time, the influence of a fluid (air in our case) in the pressure sensor's cavity was investigated during the designing of the sensor using fluid-solid interaction (FSI) (Fig. 13,14) finite element analysis. This kind of numerical simulation was important in order to compare the results with purely structural FEA where no air is present which is easiest to perform and less time consuming. 


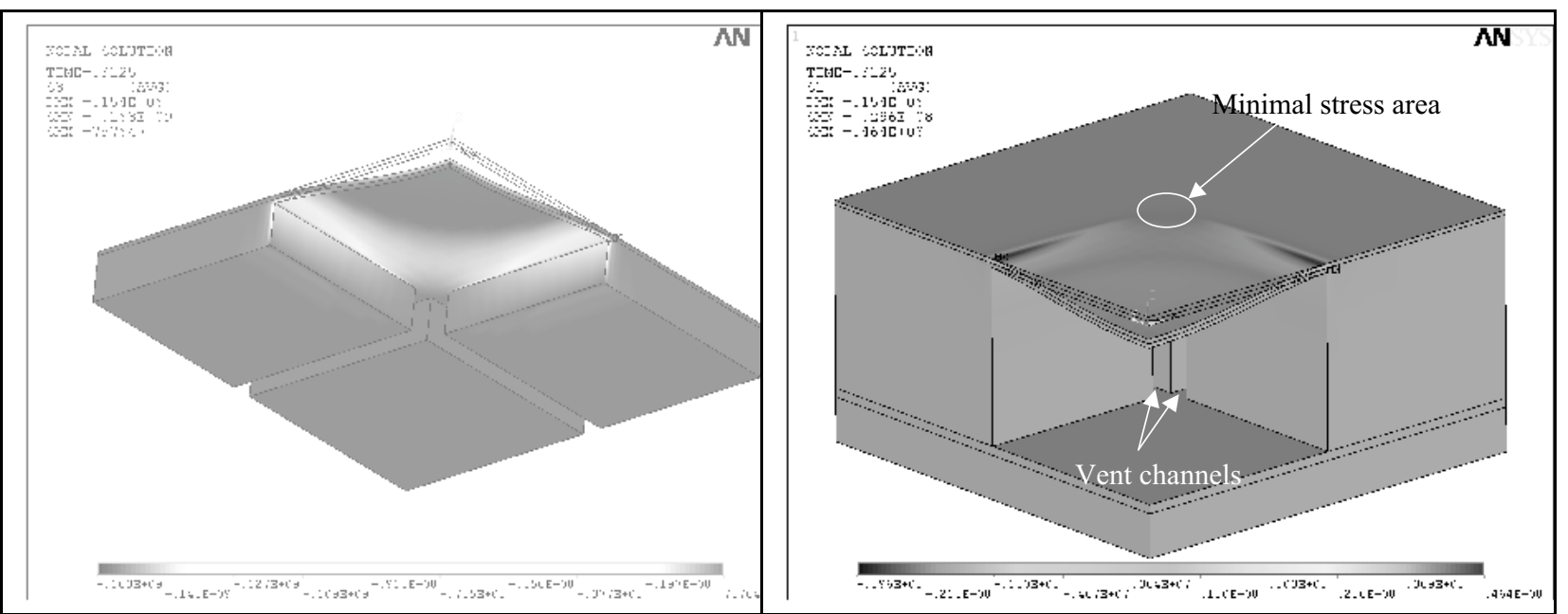

Fig. 10. Compressive $(\mathrm{S} 3)$ stresses $[\mathrm{Pa}]$ in the pressure Fig. 11. Tensile $(\mathrm{S} 1)[\mathrm{Pa}]$ stresses in the pressure sensor's sensor's structure due to pressure of $10^{5} \mathrm{~Pa}$ applied (memb. $=$ structure submitted to $10^{5}$ Pa pressure $\left.100 \times 100 \times 2 \mu \mathrm{m}^{3}\right)$. $\quad\left(\right.$ membrane $\left.=100 \times 100 \times 2 \mu \mathrm{m}^{3}\right)$.

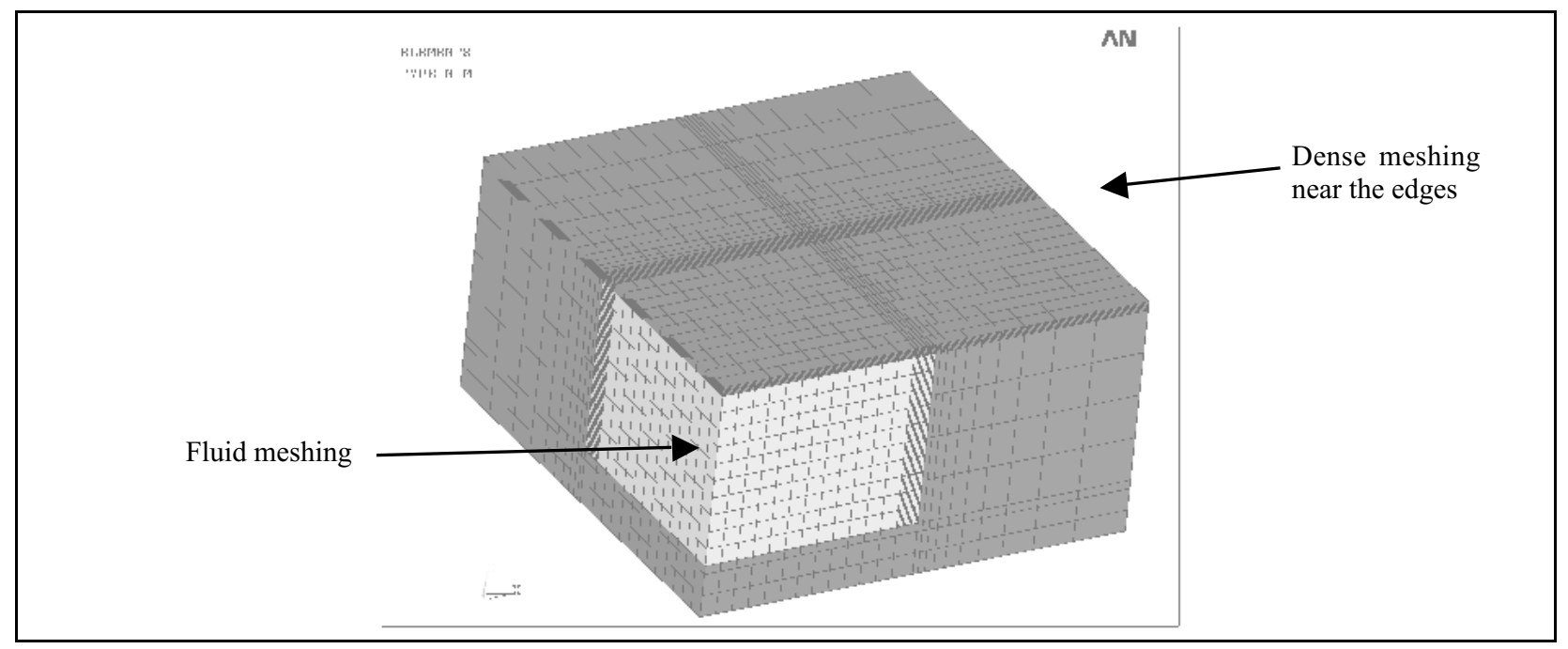

Fig. 12. Meshing details of the 1/4 (symmetry used) 3D model of the pressure sensor used for FSI simulations $\left(\right.$ membrane $\left.=100 \times 100 \times 2 \mu \mathrm{m}^{3}\right)$.

The use of a parametric model facilitated the design and the optimization of the sensor by greatly reducing the development time. Many parameters were studied and the most important of them are of course the positioning and size of the piezoresistive gauges (Fig. 15) in the pressure sensor's membrane, the size of the membrane, its overall thickness (Fig. 16) and the cavity depth. The need of differential pressure sensing has to be addressed also by minimizing its impact on the sensor's sensibility and on its overall cost. Finally, the solution of vent channels originating from the sensor's cavity corners has been adopted. The reason is that there the stresses are minimal so their presence has practically no effect on the sensor's sensitivity as it is shown by the FE analysis. In this case also an FSI numerical simulation has been carried out in order to optimize the design and avoid any undesired effects as much as possible prior to fabrication. 


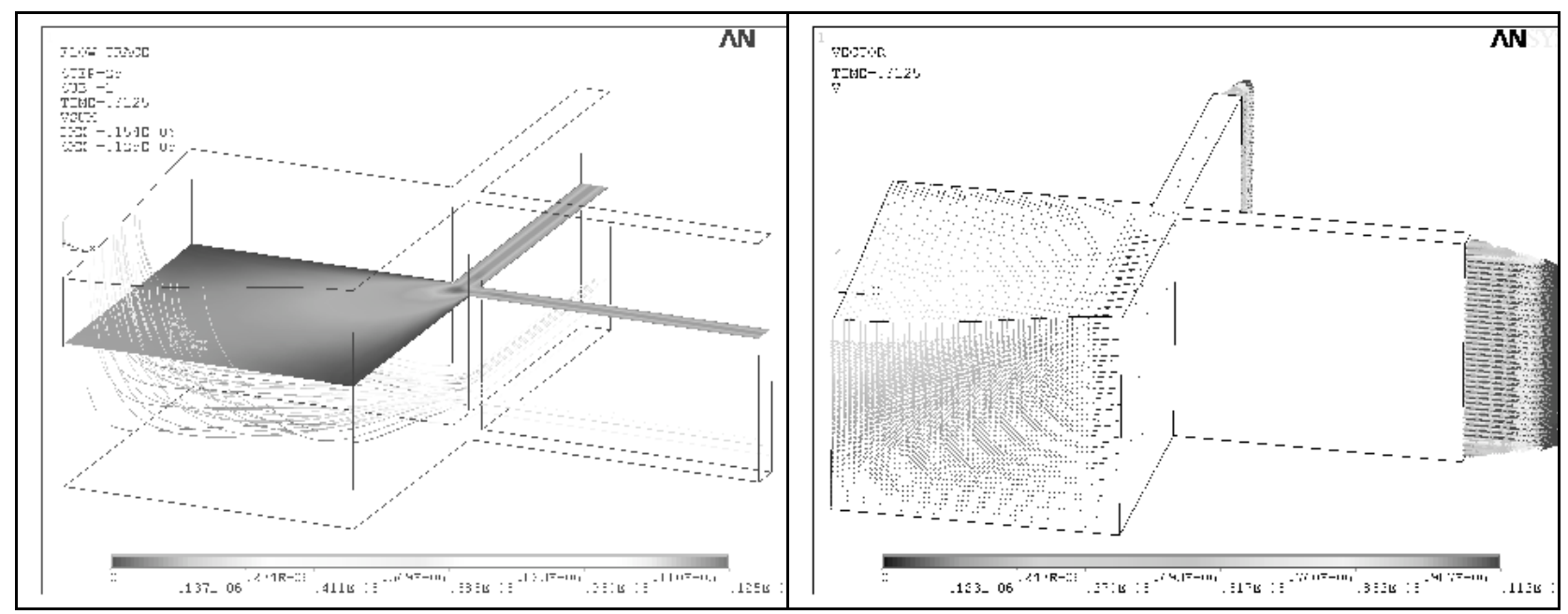

Fig. 13. FSI results in the fluid domain. The velocity of the Fig. 14. Vector plot of the velocity of the fluid (air) inside the fluid (air) at a specific section of the fluid and the traces of the fluid flow are presented (velocities are in $[\mathrm{m} / \mathrm{s}]$ ). pressure sensor's cavity and vent channels after a pressure of $10^{5} \mathrm{~Pa}$ has been applied on the sensor's membrane.

As it is already mentioned in the first part, the piezoresistive gauges are incorporated into the sensor's membrane by ion-implanting the silicon layer in order to achieve greater piezoresistance coefficients. The dose and energy of the ion implantation have been determined by using Silvaco ${ }^{\circledR}$ Athena technological simulation FE tool. The doping profile has been extracted in order to calculate more accurately the sensitivity of the gauges.
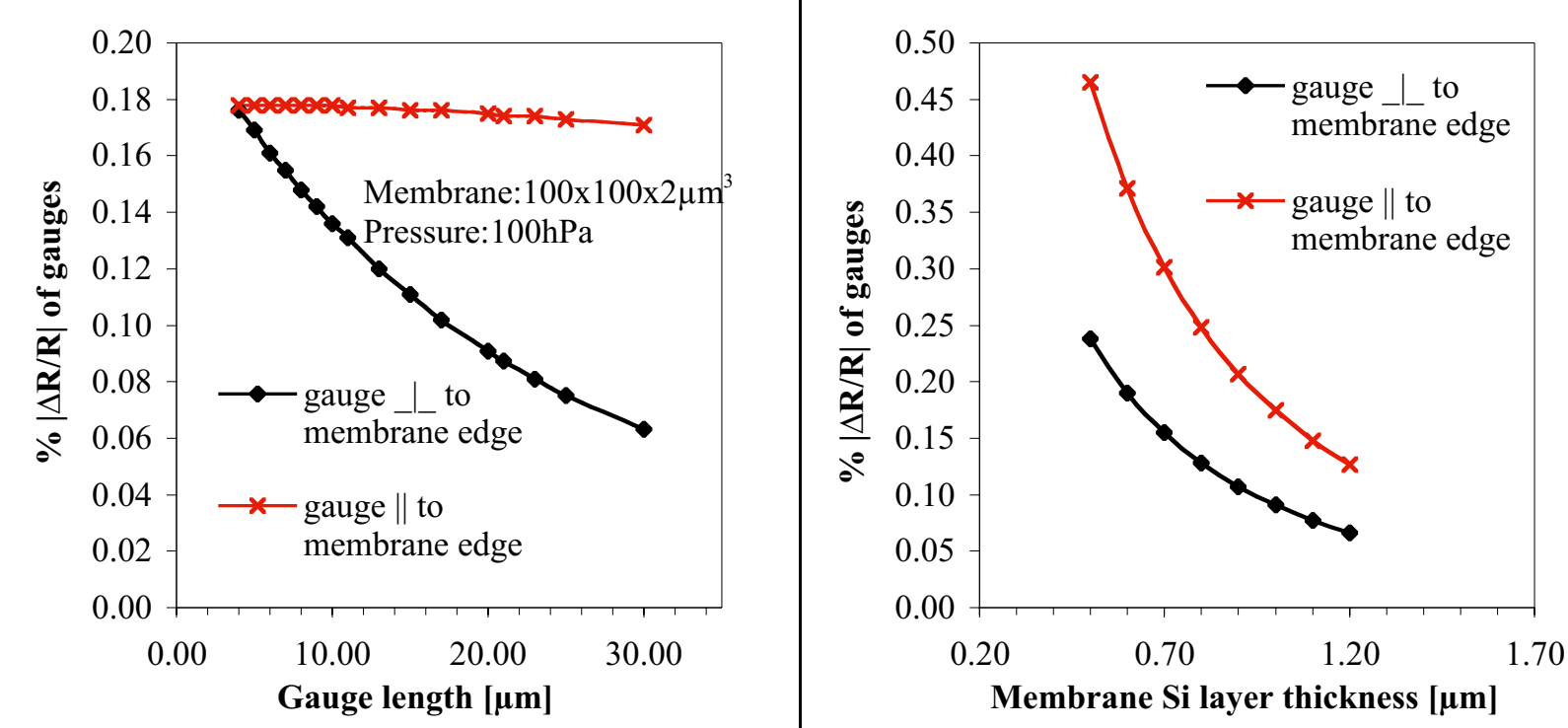

Fig. 15. Simulation results of the evolution of the resistance of Fig. 16. Evolution of the gauges resistance as a function of the the piezoresistive gauges as a function of their length. The silicon layer thickness. The gauges thickness has been pressure on the membrane was $10^{4} \mathrm{~Pa}$ and the gauges' width considered equal to the silicon layer thickness. The results may equal to $2 \mu \mathrm{m}$. The gauges were positioned at $2 \mu \mathrm{m}$ off the differ depending on the doping profile of the gauges. membrane's edge.

Experimental results on the pressure sensor are not presented in this paper because the first samples became available only 2 weeks before its submission and the calibration of the sensors has not been completed yet due to technical 
problems. We hope that until the venue of the SPIE conference the first results will be ready for publication and for presentation.

\subsection{Hotwire anemometer and thermal wall shear stress measurements}

Various characterization methods of wall shear stress sensors were undertaken. First we have calibrated the sensors in temperature. After that, we have estimated the response time in constant current and constant temperature modes. Finally, the sensors were calibrated in a low-speed wind tunnel.

\subsubsection{Temperature - Resistance setup and results}

The resistance-temperature behaviour, specially the Temperature Coefficient Resistance (TCR), is necessary to calculate the sensor overheat ratio $\left(a_{R}\right)$ for a given resistance.

The TCR is experimentally defined with an indirect heating achieved by Joule effect: TCR $=\left.\frac{1}{R} \frac{\partial R}{\partial T}\right|_{T_{0}=0^{\circ} \mathrm{C}}$.

The resistance overheat ratio is defined as $a_{R}=\frac{R-R_{a}}{R_{a}}$, where $\mathrm{R}$ is the sensor resistance at the operating temperature and $\mathrm{Ra}$ is the wire resistance at the ambient temperature.

The obtained TCR values are very depending of material, deposition method and thickness. The nominal resistance value of a $50 \times 2 \times 0.5 \mu \mathrm{m}^{3}$ polysilicon wire, doped at $10^{20} \mathrm{~cm}^{-3}$, taken at room temperature is about $3 \mathrm{k} \Omega$. Thermal electrical measurements give a TCR of $0.145 \% /{ }^{\circ} \mathrm{C}$ (Fig. 17).
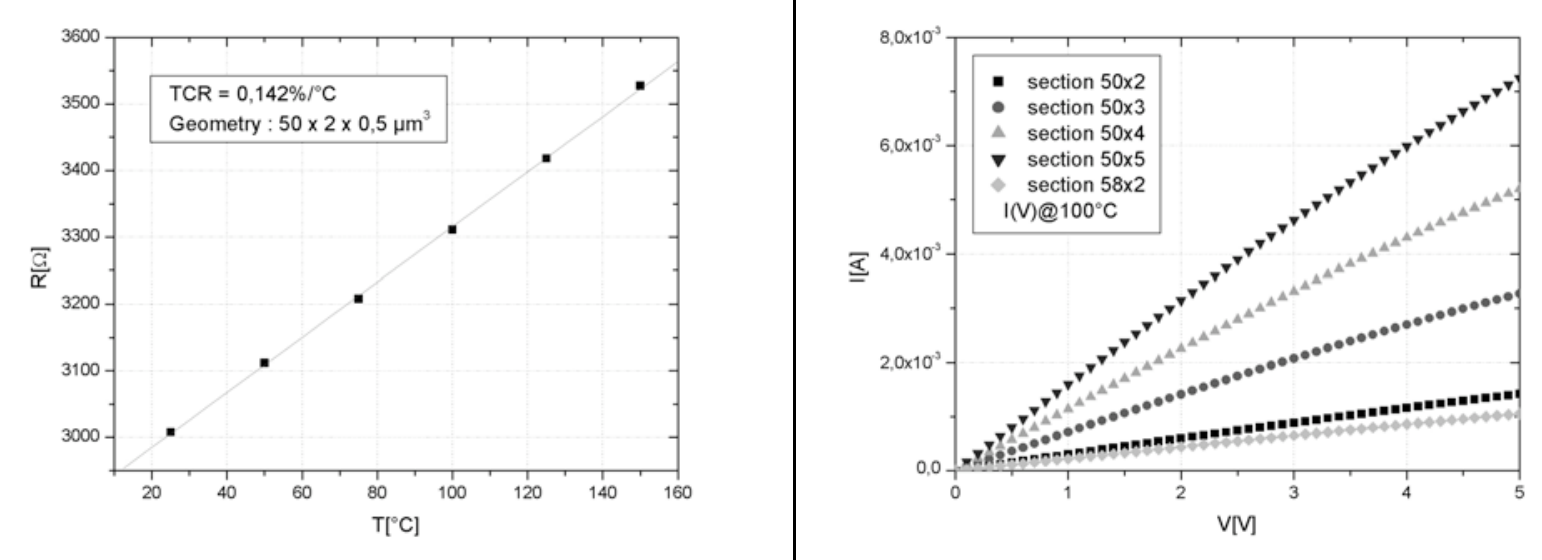

Fig. 17. Resistance variation as a function of temperature (TCR) Fig. 18. I(V) characteristics as obtained for various wire of a $50 \times 2 \times 0.5 \mu \mathrm{m}^{3}$ polysilicon hotwire. geometries.

We have also measured $\mathrm{I}(\mathrm{V})$ curves of sensors with different widths and lengths. As we can see on Fig. 18, the thinnest and longest one exhibits higher voltage for small current. The over heat ratio $a_{R}$ gives the sensors sensitivity. $20 \%$ of variation can be achieved with a constant current of $1.4 \mathrm{~mA}$ for a $50 \times 2 \times 0.3 \mu \mathrm{m}^{3}$ wire (Fig. 19), but for a $50 \mathrm{x}$ $4 \times 0.5 \mu \mathrm{m}^{3}$, the needed current is about $4.55 \mathrm{~mA}$, so about three times more. 


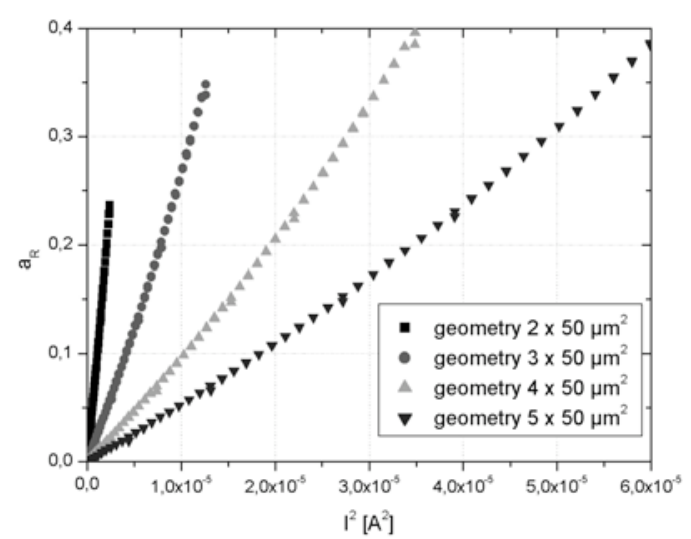

Fig. 19. $\mathrm{a}_{\mathrm{R}}$ coefficient in function of $\mathrm{I}^{2}$ for various wire geometries.

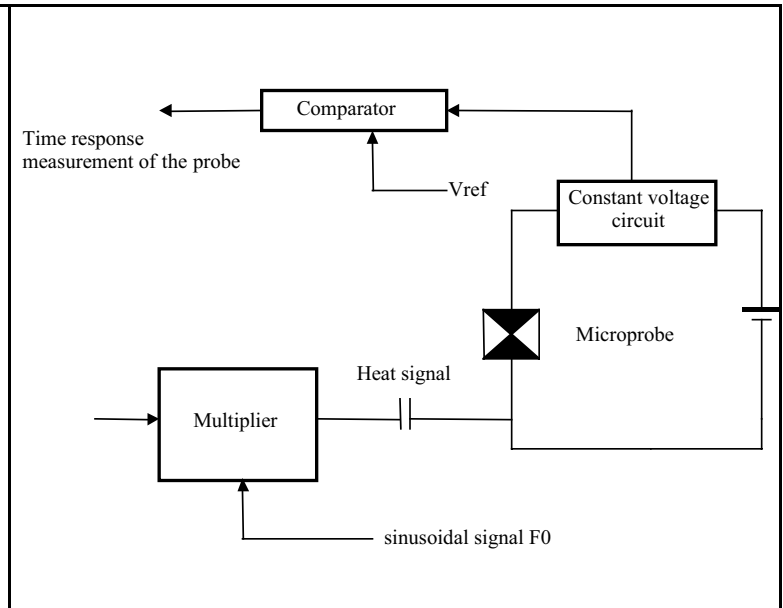

Fig. 20. Time response measurement circuit.

\subsubsection{Time Response and measurement methods}

Although static measurement is founded on a simple principle, it is now accepted that the frequency response of such sensors is in general complex because of convective and conductive heat exchanges. An electric circuit based on the internal heating method was designed and carried out for the dynamic response time determination of the sensors (Fig. 20).

The circuit makes possible to simulate, on the sensor level, the fluctuations of temperature by carrying out an internal modulation of heating of the probe created by a D.C. current (rated current of the probe). To this current, a AC current of $1 \mathrm{MHz}$ frequency modulated by a square signal of $1 \mathrm{kHz}$ frequency is superimposed. Figure 21 shows the time response of a $58 \times 2 \times 0.5 \mu \mathrm{m}^{3}$ hot wire, which is about $150 \mu \mathrm{s}$. The bandwidth sensor lies between 0 and $1 \mathrm{KHz}$, which is not enough to detect all turbulence phenomena associated with airflow over aircrafts in wind tunnels.

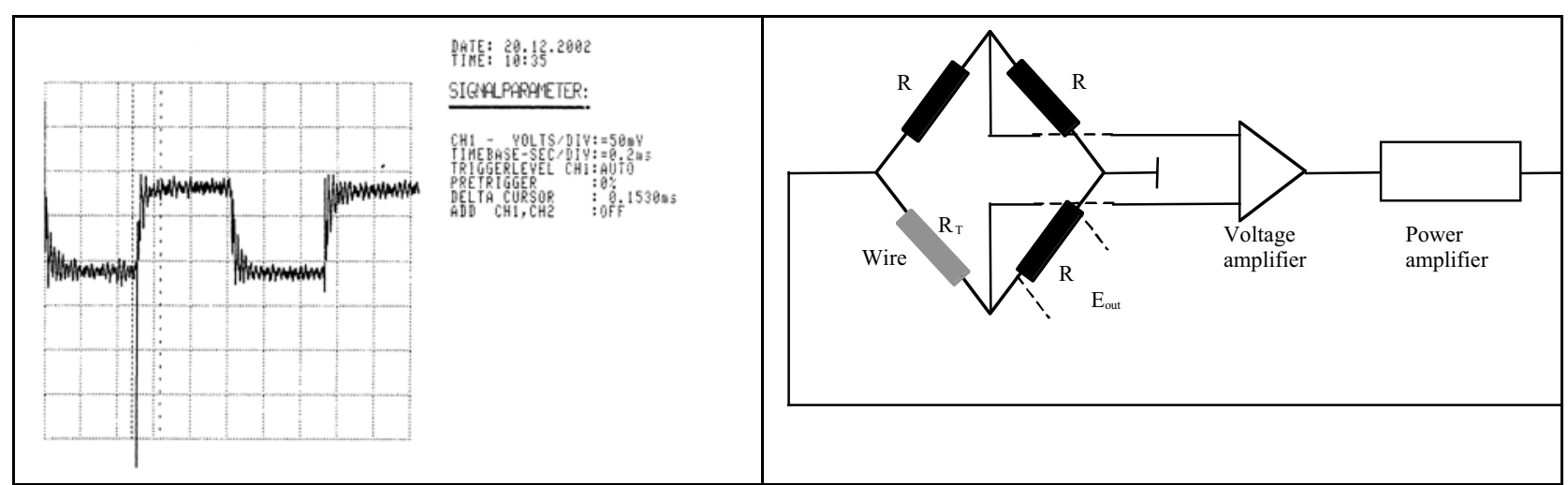

Fig. 21. Time response measurement of a $58 \times 2 \times 0.5 \mu \mathrm{m}^{3}$ wall Fig. 22. Schematic diagram of hot wire mounted in Constant shear stress sensor.

Temperature Mode.

\subsubsection{Time response study in function of the geometry}

A study comparing the time response of various hot wire geometry was undertaken. The obtained results are in agreement with the analytical model $[5,6,7]$ where the time response is calculated for constant current mode (CCM), with the next formula: $\tau_{v}=\frac{M C}{U\left(v_{0}\right) A-i_{0}^{2} K_{\theta}}$, where $\mathrm{M}$ is the sensor mass, $\mathrm{C}$, the sensor specific heat, $\mathrm{U}$ the convection heat transfer coefficient between fluid and sensor, equal to $0.65 \mathrm{Wcm}^{-2 \circ} \mathrm{C}^{-1}, \mathrm{~A}$ is the cross section, $\mathrm{i}_{0}$ the current passing through the wire and $K_{\theta}=\frac{\Delta R_{\theta}}{\Delta T}$. On figure 23, one can see that the time response is dependent on the cross section wire: the smaller is the width, the shorter is the response time. We can also note that the experimental values are fitting 
very well the theoretical model. The time response could be improved in mounting the hot wire in a Constant Temperature Mode (CTM) (Fig. 22).
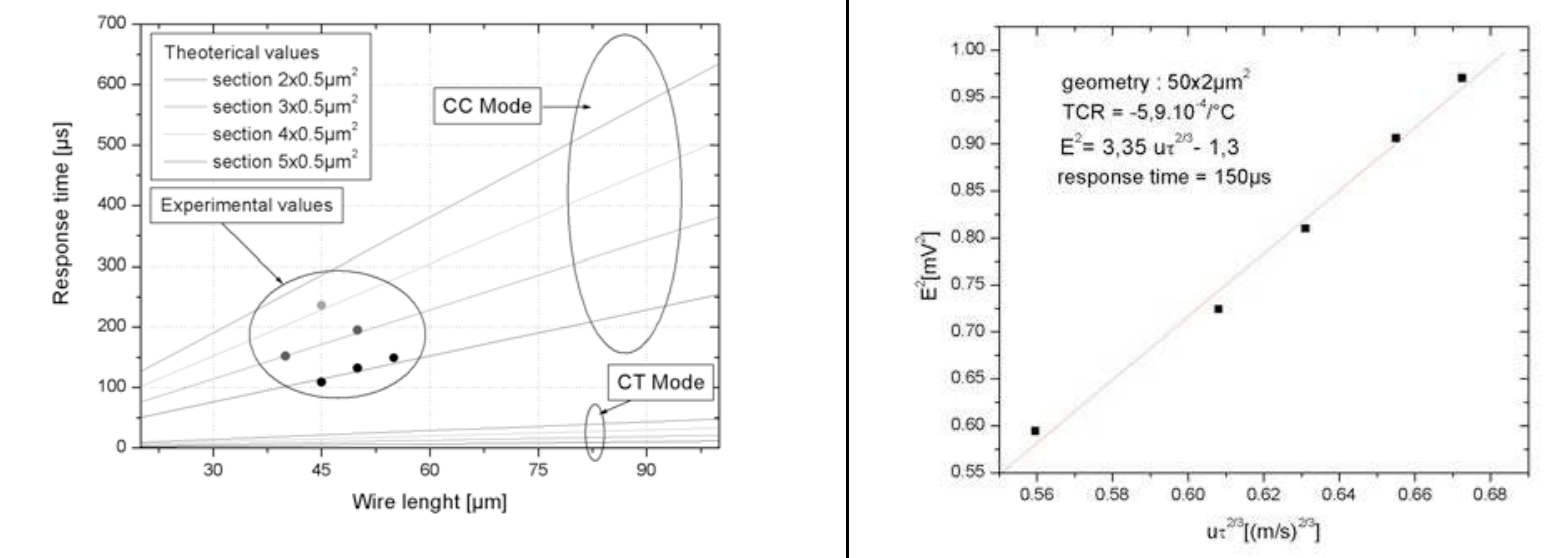

Fig. 23. Theoretical time response comparison between Constant Fig. 24. Static speed calibration in wind tunnel: $\mathrm{E}^{2}$ plot as a Current Mode and Constant Temperature Mode. Fitting of function of $\left(u_{\tau}\right)^{2 / 3}$, where $u_{\tau}$ is the friction speed. experimental values for the CC Mode.

The hot wire anemometer is mounted in a Wheatstone bridge: This is a self-balancing bridge that maintains the resistance $R_{T}$ of the sensor at a constant value $R$. An increase in fluid velocity $v$ causes a decrease of $T$ and $R_{T}$ values inducing an unbalancing of the bridge. This causes the amplifier output current and current through the sensor to increase thereby restoring $\mathrm{T}$ and $\mathrm{R}_{\mathrm{T}}$ to their required values.

The advantage of such CTM circuit is to minimize thermal inertia of the sensors, which was leading to rather bad time response. It was demonstrated $[5,6,7]$ that the time response in CTM becomes:

$\tau_{C T A}=\frac{\tau_{v}}{1+K_{I} K_{A} K_{B}}$, with $K_{I}=\frac{2 K_{\theta} i_{0} R_{\theta 0}}{\left[U_{v 0} A-i_{0}^{2} K \theta\right]}, K_{A} \approx-4$ and $K_{B}=\frac{1}{4} \frac{V_{s}}{R}$ where Vs is the bridge supply voltage and $\mathrm{R}$ the variable resistance. In figure 23 the theoretical time response comparison between CCM and CTM is presented. For our sensors, it means that the sensor time response will decrease of about 22 times. The covered bandwidth will lie between 0 and $25 \mathrm{kHz}$, which is largely sufficient for most of turbulence measurement applications.

\subsubsection{Calibration in Wind Tunnel}

Wall shear stress sensors were also characterized in a wind tunnel in order to calibrate them for static speed variation. Experimentally, the hot wire anemometer is mounted at the wall surface of the wind tunnel. A Pitot tube measures the pressure in the centre of the tunnel. This pressure is then transformed in order to know the macroscopic speed. This calibration was done for speed ranging between $5 \mathrm{~m} / \mathrm{s}$ and $15 \mathrm{~m} / \mathrm{s}$. With this constant temperature configuration, we can find the various parameters $\alpha, \beta$ and $\mathrm{n}$ of the electrical calibration of the sensor described by a law as: $E^{2}=\alpha \cdot\left(\overline{u_{\tau}}\right)^{2 n}+\beta$, where $\mathrm{E}$ is the output voltage and $\mathrm{u}_{\tau}$ the friction speed.

In measuring the output voltage variations, we can determine the other coefficients. According to Leveque solution, $\mathrm{n}$ coefficient has to be close to $1 / 3$. In figure 12 , one can see that the above-mentioned law fits perfectly the experimental values when $\mathrm{n}$ is taken equal to $1 / 3$.

\section{CONCLUSIONS}

This technology based on the use of SOI wafers and wafer-bonding technique requires only 8 photolithographies and masks. The principal advantage of such technology is to keep reproducible and constant pressure sensor cavity's depth and membrane's thickness, which is a mandatory criterion for the arrays configuration. Another advantage is that the 
pressure gauges are in monocrystaline silicon and exhibit consequently very high sensitivity. Finally, this technology offers various thermal isolation architectures for the hot wire anemometer. In the future, signal processing integrated circuit will be integrated on the same chip. The first wall shear stress calibrations demonstrate the feasibility of most turbulence fluctuation measurements. Pressure sensors measurements will be added at the conference.

\section{REFERENCES}

1. Jiang et al., Flexible shear stress sensor skin for aerodynamics applications, MEMS'99.

2. Lofdahl et al., Small Silicon Pressure Transducers for Space-Time correlation measurements in a flat plate turbulent boundary layer, J. Fluids Eng. 116, 457-463, 1996.

3. Lofdahl et al., MEMS applications in Turbulence and Flow Control, Prog. in Aerospace Sci, 35, 101-203, 1999.

4. Meunier et al., Realization and simulation of wall shear stress integrated sensor, Therminic 02 Workshop.

5. Meunier et al., Fil chaud dans une micro cavite et capteur de pression en technologie MEMS, Congres SHF "Microfluidique" - Toulouse - decembre 2002

6. Q.-Y. Tong, U, Gosele, "Semiconductor Wafer Bonding: Science and Technology,", Chapter 4, 1999, The Electrochemical Society Series, John Wiley\& Sons, Inc.

7. J. P. Bentley; Principles of measurements systems.

8. B.C. Gale; An Elementary Introduction to Hot Wire and Hot Film Anemometry, DISA Technical Publication. 